\title{
The Occurrence of Aesthetic Ethics in Primitive Society: Marx's Perspective of Objective Sensibility
}

\author{
Xinshu Zhao ${ }^{1, *}$ Xin Liu $^{2}$ \\ ${ }^{1}$ School of Marxism, Zhejiang University, Hangzhou, Zhejiang, China \\ ${ }^{2}$ Convergence Media Center, Kweichow Moutai Group, Zunyi, Guizhou, China \\ *Corresponding author.Email: 727906015@qq.com
}

\begin{abstract}
The objective sensibility that characterizes the essence of the perceptual relationship is the core and essence of Marxist philosophy of social practice theory and social history theory. Marx made a thirdorder interpretation and stipulations for the development of human society in Economic Manuscript of 1857-1858. In the primitive society of human society's first stage, the aesthetic ethics of objective sensibility reveals as a direct characteristic, manifested as the direct unity of objective sensibility and ethical reality. Carrying out the research on aesthetic ethics of primitive social sensibility and objectivity is of indispensable primary value in examining Marx's social aesthetic thought.
\end{abstract}

Keywords: original, perceptual objectivity, aesthetic ethics, directness

\section{INTRODUCTION}

The concept of objective sensibility originally originated in Marx's early PhD Thesis and Paris Manuscript, which used the concepts of perceptual and objectivity a lot. It should be noted that in Marx's text, sensibility and objectivity are used separately, but connotation of the two are meaningfully colligated. As we all know, the concept of sensibility is famous in Feuerbach, while Marx's has eliminated the natural and intuitive defects of positivism of it in Feuerbach's field of vision, and has been integrated into Marx's unique social historical field of vision. Taking perceptual objectivity as the starting point and thread, analyzing the aesthetic ethics in the primitive society of and exploring the relationship between perceptual and aesthetic ethics has become the purpose of this article.

\section{THE ETHICAL SITUATION AND MORAL}

\section{REALITY OF PRIMITIVE SOCIETY}

In Economic Manuscripts of 1857-1858, Marx stipulated the development form of human society as the society of human dependence, the society of human independence based on material dependence, and the society of human free and comprehensive development. "Human dependence (which happened completely naturally at first) is the initial social form. Under this form, human productivity only develops within a narrow range and in isolated locations." ${ }^{1}$ The primitive society with human dependence as an abstract

Karl Marx/Friedrich Engels Collected Works (Volume 46, Volume 1), Beijing: People's Publishing House, 1972, p. 104. expression is a "natural economy" society based on the perceptual natural economy with extremely low productivity and extremely underdeveloped division of labor. The original community is represented by the direct dependency of the individual in the context of blood relationship or geographical relationship. The object relationship between the individual and the community is represented by the pregnancy relationship, that is, "the community is the entity, but the individual is only appendages of the entity, or purely natural parts of the entity" ${ }^{2}$. Within the community, productivity is extremely low, and production is carried out in isolation within a narrow range with the value of sustaining life and ethnic continuity. Therefore, a firm and unbroken interdependence and close unity of existence maintain the life of the people in old time. "Nature was initially opposed to people as a completely dissident, infinitely powerful and unsubdued force, and people's relationship with it is exactly like the relationship between animals with it," ${ }^{3}$ humans in the infant's "like livestock obey its power, therefore, this is a pure animal consciousness (natural religion) on nature." ${ }^{4}$ The initial people in front of nature are weak and empty, the internal relations of life are integrated and reduced to obedience to nature, the dialectical unity of personal and human beings' sociality and independence have not

Karl Marx/Friedrich Engels Collected Works (Volume 46, Volume 1), Beijing: People's Publishing House, 1972, p. 474.

Karl Marx/Friedrich Engels Collected Works (Volume 3), Beijing: People's Publishing House, 1960, p.35.

Karl Marx/Friedrich Engels Collected Works (Volume 3), Beijing: People's Publishing House, 1960, p.35. 
yet been developed. The single existence, the primitive community formed by blood or region and the existence of the species as a whole are directly unified.

Under the natural religious ethics of human dependence, the primitive ethics of the relative people based on blood and family relations, maintained the holistic community through the continuation of the species and the violent confrontation against the alien aggression. Within the primitive community, the moral form is embodied as an aggressive holistic ethics that preserves the survival and continuation of the primitive community embodied by the diligence, tenacity, courage, honesty, enthusiasm and other qualities developed by people who use nature as an intuitive request object. What's more, in order to maintain the holism of the community, the "system" and the "standard" of all behaviors are gradually prototyped. These are the prototypes of two forms of morality. It can be seen that the internal morality of the primitive society depends on the external ethics, which is the morality of ethics, and the holism under natural religion is the common orientation of the unity of morality and ethics. Moreover, the ethical and moral concepts of the primitive society have not been rigidized into a rigid modern legal order. Holistic ethical morality unifies the individual's ethical ideals with the clan's ethical ideals, but there only are plural "classes" of the clan tribe without the singular person. Therefore, for "species" and benefit "species" are the perceptual nature and ethical reality at that time, and the existence aesthetics based on natural religious ethics annotated Communicability ${ }^{5}$ of the power of common sense and the universality of ethical beauty in the natural philosophy opened by mankind.

In the ethical norms of holism, because the mind structure of the forefather has not been fully developed, the primitive society gradually derived imitation behavior. Imitation is for the purpose of preserving the "traditional habits" and maintaining the public will of the ethnic group. This function in turn proves the ethical norms of the holism in the primitive society. The ethics in the primitive society is represented by a series of established taboos and etiquettes. Due to the scattered living of primitive society, these taboos and etiquettes appear in different forms in different periods and different regions. But they all share a similar core theme, which is to maintain the existence of ethnic groups and promote the development of ethnic groups. Inspired by this holistic ethics, all members of the ethnic group unconditionally and unconsciously obeyed the public will. It can be seen that the holistic ethnic identity is the earliest ethical consciousness of mankind. Due to the extremely low productivity of humans in the

"Common Sense" and "Universal Communicability" are the social concepts and empirical elements of aesthetics in the "Analysis of Beauty" section of Kant's Criticism of Judgment. early days, the language system has not yet been nurtured and developed. Ethical awareness is only in its infancy and not yet recognized by first-timers. At this time, imitation became the first tool and means of inheriting ethical and moral consciousness. In fact, the early imitation of human beings is a realistic activity interwoven with material and verbal communication, the consciousness of which is reflected in its highly meaningful and ethical nature. Therefore, imitation, as an important behavior in primitive society, is an important carrier to explore the origin, formation and inheritance of ethical and moral consciousness in primitive society, and it is also of great value in exploring the aesthetic meaning in primitive society.

To sum up, the imitation activity has kept the identity as the survival activity of holism. The original imitation itself is an unconscious means of survival for the early people to seek advantages and avoid harm under the action of natural force majeure, to adapt to and reform the environment in order to maintain themselves. In addition to the dependence of individuals on ethnic groups in primitive society, any activities carried out are mixed with strong collectivism, which is infiltrated in any form of activities not only as a dynamic element of material production, but also an decisive element occupying and influencing spiritual production.

Here, it is necessary to distinguish the difference between human imitation and pure animal imitation. In non-human higher animals, imitation, as a way of behavior, has also existed widely, but it is all unconscious. Although higher animals have the same complex group structure, show the same form of group activities, and cooperatively hunt with each other, such as lions. The reason why these higher animals can only be animal existence but not a primate is its inability to make tools. Their survival activities depend directly on nature, completely obey the law of cause and effect established by nature, and have no creative ability beyond instinct. That is to say, non-human higher animals have not distinguished themselves from nature in terms of consciousness and behavior. The individual differences among the ethnic groups of higher animals are only biological natural differences, such as age, gender, coat color, etc., and the way of their activities is still a simple identity and repetition that is instinctively required, even if it is the behavior of using natural tools. In general, it is only an instinctive copying activity. The evolution of animals is entirely determined by changes in the natural environment, that is, driven by external forces. Only when people began to consciously manufacture and use tools in order to fight against nature and maintain themselves to a certain extent, the animal's group structure in their bodies turned to become a completely new human social structure. Tool manufacturing has enabled mankind to break through the biological restraint, break the shackles of the causal 
law imposed on itself, and gradually cultivate its own social structure and social interaction between individuals.

Each generation learns the experience from the realistic material created by the previous generation, and learns the method of creation by repeating and imitating the footprints of its predecessors. The tools that have been created are the materialized and realistic experience condensation. According to the changed environment, the traditional methods learned will be reformed according to the time so as to realize the inheritance of civilization. In this process, repetitive activities expose common and similar components in different types of activities, which eventually accumulate as the psychological basis for the skills to be imitated. Piaget's theory confirms this: the structure of thinking comes from the results of actions. The skills inherited and developed through repetitive imitation constitute the key to the internalization of external activities into early human collective psychology. It is a confirmation that the imitation activities of early humans have exceeded the direct biological purpose. The formation of collective psychological representation reflects the identity of mimicry and survival for the early humans. It can be said that in the primitive society, the imitation activities represented by the use of tools have both a production function and a communication function. In the early days of mankind, imitation "activities and movements are not only a profound foundation for conceptual activities, but also a way and means of transforming from outside to inside." 6 This internalization of moral psychology gradually nurtures the human's internal demand for perceptual spiritual content.

\section{PERCEPTUAL SPIRITUAL CONTENT PRODUCED UNDER THE ETHICAL REALITY OF PRIMITIVE SOCIETY}

The moral reality "practice" of the early people's obedience to natural religious ethics is an intuitive and perceptual process that differs from the pure unconsciousness and non-objectivity of animals, revealing the spiritual creation and value exploration of humans' intuitive objectification of nature. Here during the period, the fantasy imagination that embodies the sensual consciousness and object consciousness gradually germinates, which is the conceptual expression of the aesthetic consciousness. "On the one hand, as far as nature is both being created and destroyed, in general, in the sense that it gives a prominent and powerful impression, people make it humanized as the Almighty; on the other hand, as far as nature creates countless enjoyments are concerned, in

6 Ferbach: Philosophical Works Collection (Volume 2), Beijing: Commercial Press, 1984, p.826. general, as far as the impression of supreme goodness given by it as the sum of all goodness and beauty in life, man turns it into a supreme one; as far as nature produces all these things in an way to promote rationality somehow inexplicable, people have made it a wise man and almighty man." 7 The naturalized personified god and the nature endorsed by humanized god as the sensuous spiritual objects of the initiative people show off "the manifested nature of man is the real and objective 'I' of man" ${ }^{8}$. That is the objective germination that the early people seen and cast on the object. The ability of perceptual objective at this time is intuitive, so it is a limited and incomplete aesthetic judgment. The nature of objective nature does not have actual contact with the early people, but the objective nature presents the most direct meaning to the people with a perceptual representation. When the purpose meets the subject, it is the satisfaction of the subject's needs, thereby triggering unconscious pleasure. At the same time, nature surpassed the empirical power of the "imagination" and "intellectual power" of the people with its tremendous volume in mathematics and mechanics and the force majeure and unpredictability of natural events, which is extremely repressed upon the ability of perceptual objective and turns into the object people fear, then gives birth to an original and unconscious "sublime sense". This is the connotation logic of natural ethical reality and intuitive perceptual spiritual production.

Feeling is the actualization of perceptual ability. The form of perceptual consciousness of natural religion in the minds of newcomers is the thinking prototype and spiritual embryo of the quasi-essential objectification of "total richness": "Not only the five senses, but also the so-called spiritual sense, practical sense (will, love, etc.), in a word, human feelings and human nature of feelings are only due to the existence of its objective and human nature." ${ }^{9}$ Although Marx wrote it about the new human nature of communism, it is also applicable to the initiation period of the intuitive humanity and objectivity of the "human childhood" when the humanity of the sense has not been alienated by private ownership. It can be seen that the human nature of sensation (spiritual and practical) depends on the realization of the objective reality of sensation, which constitutes the preparation of the anthropological aesthetic consciousness of the objective sensibility. In a word, the sensibility perceptually forms in psychology directly depends on the spiritual production of perceptual objective in intuitive empirical upon nature. The mental perception of intuitive perceptual

Ferbach: Philosophical Works Collection (Volume 2), Beijing: Commercial Press, 1984, p.826.

$8 \quad$ German Philosophy in Late Eighteenth Century and Early Nineteen Century, Beijing: Commercial Press, 1975, p. 547.

Marx: Manuscript of Economics and Philosophy in 1844 . Beijing: People's Publishing House, 2018, p.84. 
objectivity is the consciousness reproduction and spiritual product of the primitive people's obedience to natural religion and objectification of their own nature.

Perceptual power is the objective manifestation and basic provisions of "human essential power". Aesthetics based on sensible perception as the physiological basis and objectivity as the basis of consciousness are sensuous feelings of "the real existence of the person who has not been alienated". "Human beings as objective and sensuous beings are driven beings; they feel they are driven, therefore they are passionate beings. Passion and enthusiasm are essential power that people strongly pursue their objects." 10 "Passion" expressed as virtue qualities such as diligence, bravery, honesty, enthusiasm, etc. is the original aesthetic sentiment of the ethical reality of the early people based on natural religion, and it is the original "sensual explosion" of human essential power-although it has not yet become "being aware of the existence": "The domination of the essence of objectivity in me, the perceptual explosion of my essential activity is passion, and here the passion becomes my essential activity."11 Intuitive perceptual objectivity, as the primary and basic rule, links intuitive natural reality, natural community and human essential power, and Marx endows it with the importance of ontology and constitutes its perceptual object paradigm. Therefore, in natural religious ethics, natural humanization includes both intuitive external natural humanization (empirical nature), as well as the internal humanization of human beings as living bodies (emotional shaping). Both of which through perceptual activities "act on the nature outside him and change the nature, his own nature has been changed at the same time"12 Obtaining intuitive perceptual objective relationships, human sensible consciousness and aesthetic psychology grow its roots.

Although the primitive society's perceptual objectivity is a kind of intuitive sensibility and intuitive objectivity based on the concealment of human consciousness and human's mechanical obedience upon natural, conclusively it is incomplete. But it is hard to conceal the glory of Marx's dialectical rule of sensible objectivity paradigm, which surpassed the "inhumanity" of idealistic rationality with realistic and historical vision, and surpassed the old materialist with the dialectical thinking of the unity of subject and object. Intuitive perceptual objectivity is the process in which perceptual consciousness begins to unfold. It is also the beginning of conscious morality that transcends the foolish savage ethics in primitive, and the beginning of

10 Marx: Manuscript of Economics and Philosophy in 1844, Beijing: People's Publishing House, 2018, p. 104.

11 Marx: Manuscript of Economics and Philosophy in 1844, Beijing: People's Publishing House, 2018, p. 87.

12 Marx: Manuscript of Economics and Philosophy in 1844, Beijing: People's Publishing House, 2018, p. 87. aesthetics. In all, the essential objectification of humans based on intuitive perceptual objectivity is a philosophical metaphysical explanation upon (intuitive) perceptiveness occurring in natural religious ethics. The original aesthetic experience and moral cultivation of the plain community begin here.

We already know that in the primitive collective, the individual is attached to the collective, whose consciousness follows the ideology of collectivism. Therefore, the individual's consciousness has not been developed. Conscious consciousness manifests as a collective common psychology, thereby binding the individual firmly within the ideology of collectivism, which is characterized by mystery and unity. Taking the totem worship as an example, the mysterious totem exists in the primitive people's imagination and spirit, playing a role of uniting and inspiring members of the tribe. Under the symbolic appeal of the totem, the emotions of all tribal members are connected into one, in which they feel a strong sense of identity and integration. This identification process is the performance of early humans intuitively objectifying themselves in witchcraft. Under the totem, the primitive human spirit is dominated by the power represented by the totem, and according to the needs, the totem will produce common ecstatic emotions, such as identity, hope, fear, etc. Perceptual spiritual activities reflect the ethical and moral consciousness in the primitive society: the holistic public will is the highest order that every member of the ethnic group must abide by. Hence perceptual spiritual activities strengthen the authority of this public will from the ideological and cultural field. This primitive totem worship activity is the cultural activity of the early human sensible and objectivity, what's more it carries out the spiritual production of collectivist moral ethics in a very solemn and strict form. In order to maintain the authority of collectivism, such spiritual and cultural activities are often full of mystery, awe, seriousness, grotesqueness, and fear. It is acknowledged that mystery and unknown cause fear, so maintaining mystery parallels to maintain the effectiveness of collectivism instillation. Therefore, the aesthetics of spiritual and cultural activities in primitive societies are often religious, as some scholars say that in primitive societies, "we found that self-sensation and a certain myth-religious group sense are directly integrated into one. Only when the self recognizes itself as a member of a group and understands that the self forms a unity of family, tribe, and social organization with others he/she feels and recognizes himself. Only by being in and through such a social organization can he own himself; his own personal survival and every manifestation of life is related to the whole life 
surrounding him, although this connection depends on a number of invisible mysterious bonds." 13

The primitive human's recognition of the totem promoted the development of imitation ability, and thus promoted the development of aesthetic ability. Aristotle had noticed this problem for a long time as follows: "Imitation is a natural tendency of human beings, which has been revealed since childhood. The reason why humans are different from other animals is that humans are the most good at imitating in the Middle of other living lives. People begin to learn by imitating. Everyone naturally gets pleasure from imitating stuffs. Since human beings have produced "selfconsciousness", they are eager to understand and handle the outer wild world to meet their own purposes and needs. Imitation is a means to master the external world. In this process, totem worship plays a special role. Due to the special close relationship between primitive humans and totems, it takes various forms to reach the mutual recognition of both sides, of which imitating the totem is one of the most important means. ${ }^{14}$

In the end, the aesthetic psychology of primitive humans lurked in the racial inheritance of higher animals (human apes), was manifested in the creation of the first art work (stone), and was developed in nature worship, totem worship, religious witchcraft, myths and legends, literature and art. That's to say, perceptual objectivity essentially shaped the aesthetic psychology of early humans. As Piaget believes, human knowledge does not originate from the object or the subject, but from the action (activity) that connects the subject and the object. The characteristic of the activity is that it is a process of interaction between the subject and the object. This process is the continuous development process of human cognition in the endless progress of assimilation, adaptation and balance, forming a cognitive psychological schema from low level to high level. ${ }^{15}$

\section{THE DIRECT UNIFICATION OF AESTHETICS AND ETHICS IN PRIMITIVE SOCIETY}

The primitive unity of ethics and aesthetics of perceptual objectivity is reflected in the saying that beauty and good are equal in ancient Chinese aesthetics, such as "perfecting the perfect" and "being happy with the good", but also reflected in Socrates's discussion of the unified theory of beauty and goodness. The original aesthetic standard was holistic

\footnotetext{
13 Ernst Cassirer: Mythical Thinking, Beijing: Chinese Social Sciences Publishing House, 1992. p.195-196.

14 Zuobang Zhang: Cultivation of Totem Worship for Human Aesthetic Psychology, Guizhou Ethnic Studies, 2007 (4), p.56.

15 Zuobang Zhang: Natural Environment and Generation of Human Aesthetic Psychology, Academic Exploration, 2008 (1), p.1.
}

utilitarianism under the direct guidance of natural religion and ethics in which ethics and aesthetics are directly coordinated, that is, all purposefulness beneficial to the maintenance of racial survival is a virtuous goodness and a perceptual beauty: "When goal is set by the subject and only for the subject, the purpose is the satisfaction of the subject's needs. Satisfaction of the subject's needs triggers the subject's joyful emotion"16. Need ability as the actualization of the intuitive objective sensibility of man, which has sprouted into the original aesthetic experience and moral experience in the primitive society. Marx affirmed the needs ability of people as following: "The rich man is also the person with needs of integrity of human life performance, in such a person, and his own realization exists as an internal necessity and as a need." ${ }^{17}$ For the first-timers, the need to maintain survival and the reproduction of races is the most important and all the contradictions of "internal necessity" and "integrity of human life performance" (sensual physiological needs). Perceptual in this time dependent on the survival needs of natural religious ethics, is limited to the simple perception upon the basic elements of sustaining life, which is an intuitive and specific perceptual objective needs.

Under such ethical and moral standards, women have become the main backbone of the family society due to their work ability (collection) and fertility, as well as the main productive power of morality and aesthetics. Therefore, the works of art in the primitive era mostly imitated the shape of animals, reflecting the straightforward aesthetic consciousness of the desire for survival and the continuation of the species. For example, the rich wild horses and bisons in the murals conveyed the early people's desire for food. The image of multi-breed frogs and fishes depicted on the patterned pottery urns and fish patterned pottery pots expresses the needs for the freedom of species survival of. Primitive humans intuitively empirical nature by collecting and hunting to manufacture and use tools and produce products according to the internal purpose and nature regularity-though they do not really "know" what they are acting-to meet the needs of intuitive sensibility, during which, intuitive sensation pleasure triggered. The "law of beauty" as original beauty of virtue has been presented.

Under the survival ethics environment of natural religions, the first generation created an artistic form embodying strong moral and surviving aesthetic meaning, based on it, primitive songs, dances, witchcraft etiquette and other aesthetic forms that

\footnotetext{
16 Zhengwen Zhang: Thinking of Modernity Thoughts: German Aesthetics Draft, Beijing: China Social Sciences Press, 2013,

17 Marx: Manuscript of Economics and Philosophy in 1844, Beijing: People's Publishing House, 2018, p. 87.
} p.156. 
entrust utilitarian wishes were developed. This reflects the unreproducible and intuitive sensible pleasure caused by the utilitarian content, such as the harvest, turning to a conscious one appealing to the development of artificial creation forms, such as primitive sacrifices and witchcraft etiquettes that pray for the harvest in order to obtain conscious, reproducible and emotional pleasure caused by harvest image stimulation. The generation of the half-conscious art forms has greatly promoted the advancement of the aesthetic awareness of the early people: on the one hand, they developed the conscious spiritual perception on the harvest image and the aesthetic pleasure behind the image, on the other hand, resorting to the primitive witchcraft form the utilitarian desire to pray for a good harvest spawns conscious pleasing moral emotion in higher-level. Under the potential guidance of aesthetic ethical utilitarian pleasure, the beginners revealed their conscious acquisition of the perceptual objective ability in the form creation and purpose interpretation in the natural process of intuitive perceptual objectification. In addition, the intuitive aesthetic appreciation consciousness of nature resulting from the harvest image is superior to the simple form of practical appliances with aesthetic and artistic meaning in the perspective of civilization evolution, confirming that the beauty was originally reflected as the purposefulness of the perceived object (free natural entity and artificial natural entity) to the subject's general perceptual objective ability. This intuitive and natural beauty is the original one, and the utility of beauty is preserved a priori in the purpose of the original natural beauty, precisely because the original natural beauty based on perceptual objectivity contains a kind of will and inquiry of bioethics upon natural religion. Finally, freedom and nature have achieved the original unity in perceptual objectivity.

The purposeful acquisition of spiritual pleasure in the intuitive perceptual needs of the early people not only evokes the conscious start of the ethical freedom, but also the beginning of the self-shaping of human nature and the formation of the aesthetic subject. The forefathers acquire the original perception of perceptual objectivity in the chaotic experience of nature religious ethics. This original perceptual objectivity starts from the reality of the inevitable law, and is a non-reflective intuitive sensibility from impression to sensation, from reality to thought. Ethical reality here is directly unified with sensibility. Forms of perceptual activities of intuitive free are the prototype of aesthetic ethics, and the art products and art forms that are the result of the activities are the objectified condensation of the perceptual freedom dimension of perceptual objective. Based on the perceptual experience of survival ethics, the senior people objectified nature and objectified themselves, and gradually awakened the consciousness of freedom. This kind of naive and simple primitive freedom seen now has been the highest state that could be reached at that time and the spontaneous poetic experience of the primitive community reaching the perfection and goodness.

With the premise of survival needs, various human activities become purposeful. The efforts of all kinds of labor have gradually brought generous rewards. The harvest of the hunt and the high yield of rice made the primitive people rejoicing. They used body language to convey happiness and blessings to each other, and tried to record these with images. At this time, beauty and aesthetic consciousness gradually emerged, so the feeling of beauty was born after the further expansion of primitive human activities, and with the further improvement of the human brain. Only when the development of human society has spiritual needs in this real sense the conscious spiritual of aesthetic consciousness settled. At the same time, the appearance of decent, hand-operated utensils was recorded in the minds of primitive people. They gradually formed the rules of beautiful form and the principle of functional beauty. When the function of the appliance has fully met the needs, it is believed that the productivity of the primitive people has greatly developed compared with before, and the evolution of the human brain has made humans have a very different aesthetic consciousness from animals.

\section{CONCLUSION}

The primitive society's sensibility has not yet been perfect, and it mainly manifests as external intuitive sensibility around feeling, perception and appearance. Based on intuitive perceptual ability, thinking cognitive ability begins to foster. Sensibility requires ability as the most primitive nature is the earliest "ideology". Needs ability determine the way of material possession, and the way of material possession determines ideology. The perceptual system embeds the elements of perceptual needs into the objective historical narrative. What kind of perceptual needs determines which kind of ideology and social historical form.

The aesthetic grasp and care upon the subject's free nature is the experience of the subject's full vitality and the sublimation of the soul, which is the ethical connotation of Marx's liberating aesthetics. However, in the human society before the construction of the Kingdom of Freedom with the banner of consciously free aesthetic relationships, the subjectivity of human beings have being enslaved and destroyed as reflected in the establishment of the imagined worlds like religious theology and the loss of human subjectivity. Cruelly, the establishment of the subjectivity of natural religion and capital religion show that human selfconfirmation and free liberation are still an unfinished project. Marx's liberation aesthetics takes objective sensibility as its ontology, and on the basis of fully 
recognizing human's subjective ability, imagines the infinite ontology with limited flesh and seeks spiritual freedom, however does not replace human's subjectivity with the infinity of supernatural gods. In religious metaphysics, man is objective, abstract and limited. Marxian aesthetic paradigm of perceptual objective abandons the existence of transcendent power-like fetish in the concept of man, and illuminates the obscure world that has been submerged for a long time by the metaphysical game. Hence it is the true subjective atheistic aesthetics returning to reality. Perceptual objectivity shows that Marx's aesthetics inherently calls for a reality beauty, content beauty, and moral beauty that transcend the beauty of form. Morality is the connotation category that represents reality, and the interrelationship between perceptual objectivity and moral reality seeks the foundation of ethical and moral connotation.

Perceptual objectivity is manifested in the phenomenal world as value reflection and ethical practice in social relations, in the ontological world as the essence of the subject's perceptual freedom, and in the aesthetic world as the aesthetic ideas and forms with the essence of free life manifestation and based on imagination. It can be seen that the perceptual objectivity is internally organically unified the ethical, philosophical, and aesthetic fields. "So the aesthetic relationship between man and the world is not only a perceptual reality, but also an inevitable ontology, reflecting psychology and physics, subject and object, phenomenon and ontology, freedom and necessity, cognition and practice, the unity of science and ethics." 18 Therefore, perceptual objectivity is not only the perceptual certainty of the intuitive perception upon specific objects, not only the conceptual certainty of the rational cognition of abstract knowledge, but the historical and practical backlash of sensibility to the certainty of rationality. It is "creating a man of all richness with human nature, creating a rich and comprehensive people with profound feelings as the permanent reality of this society." 19 "The full richness of human nature" is manifested in the phenomenon of practical materialism as "man is the sum of social relations", which is the true relational connotation of "people with rich, comprehensive and profound feelings". It is only in the ontology of perceptual relations that the individual's perceptual activities and the community's perceptual activities are unified. As Marx profoundly recognized, "Man is a special individual, and it is his particularity that makes him an

18 Zhengwen Zhang: Thinking of Modernity Thoughts: An Essay on German Aesthetics, Beijing: China Social Sciences Press, 2013. p. 158

19 Marx: Manuscript of Economics and Philosophy in 1844, Beijing: People's Publishing House, 2018, p. 84. individual and a realistic, single social being. Similarly, he is also a totality, a totality of ideas, the existence of self-contained subject of being thought and being perceived in society, just as he exists in reality both as an intuitive and realistic enjoyment of social existence and as a totality of life performance of human." 20

\section{References}

[1] Karl Marx/Friedrich Engels Collected Works (Volume 46, Volume 1), Beijing: People's Publishing House, 1972.

[2] Karl Marx/Friedrich Engels Collected Works (Volume 3), Beijing: People's Publishing House, 1960.

[3] Collection of Feuerbach's Philosophical Works (Volume 2), Beijing: Commercial Press, 1984.

[4] Zhengwen Zhang: Thinking of Modernity Thoughts: German Aesthetics Draft, Beijing: China Social Sciences Press, 2013. Kant: Criticism of Judgment (Volume 1), translated by Zong Baihua, 1985 edition of the Commercial Press.

[5] Marx: Manuscript of Economics and Philosophy in 1844, Beijing: People's Publishing House, 2018.

[6] Zhengwen Zhang: Thinking of Modernity Thoughts: An Essay on German Aesthetics, Beijing: China Social Sciences Press, 2013

[7] Zuobang Zhang: Cultivation of Totem Worship for Human Aesthetic Psychology, Guizhou Ethnic Studies, 2007 (4)

[8] Zuobang Zhang: Natural Environment and Generation of Human Aesthetic Psychology, Academic Exploration, 2008 (1).

[9] Ernst Cassirer: Mythical Thinking, Beijing: Chinese Social Sciences Publishing House, 1992.

[10] Hao Zhang: Genesis of Thinking, Beijing: China Social Sciences Press, 1994.
20 Marx: Manuscript of Economics and Philosophy in 1844, Beijing: People's Publishing House, 2018, p. 81. 